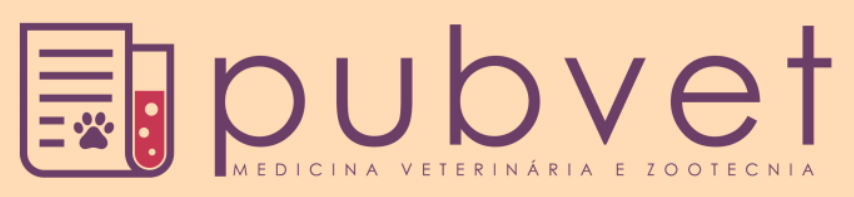

HTTP://DX.DOI.ORG/10.22256/PUBVET.V11N12.1196-1209

\title{
Abate de bovinos: Considerações sobre o abate humanitário e jugulação cruenta
}

\author{
Pâmella Stéfani Melo Mendonça ${ }^{1}$, Graciele Araújo de Oliveira Caetano² \\ ${ }^{1}$ Bacharel em Zootecnia pela Universidade Federal de Goiás. \\ ${ }^{2}$ Doutoranda em Zootecnia pela Universidade Federal de Goiás; Professora da Faculdade de Jussara/GO. \\ Autor para correspondência, E-mail: gracielecaetano@outlook.com
}

\begin{abstract}
RESUMO. Métodos convencionais, como o abate humanitário, utilizam a insensibilização antes da sangria para que os animais sejam abatidos sem sofrimentos desnecessários e para que a sangria seja mais eficiente. Já os abates que são efetuados conforme os rituais religiosos, judaicos ou muçulmanos, utilizam a jugulação cruenta. Este trabalho foi desenvolvido com o objetivo de salientar a diferença entre o abate humanitário e a jugulação cruenta, esclarecendo cada método de abate utilizado, como funciona a linha de abate, quais animais podem ser utilizados e como os frigoríficos conseguem os certificados. $\mathrm{O}$ abate humanitário e a jugulação cruenta são métodos diferentes, cada um com sua particularidade, mas que possuem o mesmo objetivo que é garantir o bem-estar animal e obter carne de qualidade para os seus determinados consumidores. O tema se faz de grande relevância já que o Brasil tem interesse econômico nos abates religiosos, e devido ao valor agregado nas negociações, aumentam-se as taxas de exportações que geram divisas não só para as indústrias como também para o país como um todo.
\end{abstract}

Palavras chave: Bovinos de corte, bem-estar animal, qualidade da carne

\section{Cattle slaughter: Considerations about humanitarian slaughter and culling cattle}

ABSTRACT. Conventional methods, such as humanitarian slaughter, use pre-bleeding
desensitization so that animals are slaughtered without unnecessary suffering and bleeding
is more efficient. Already the slaughters that are carried out according to the religious,
Jewish or Muslim rituals, use the bloody slaughter. This work was developed with the aim
of highlighting the difference between humanitarian slaughter and bloody slaughter,
clarifying each method of slaughter used, how the slaughter line works, which animals can
be used and how the slaughterhouses obtain the certificates. Humanitarian slaughter and
bloody juggling are different methods, each with its own particularity, but with the same
objective as guaranteeing animal welfare and obtaining quality meat for its specific
consumers. The issue is of great relevance since Brazil has an economic interest in religious
slaughter, and because of the added value in the negotiations, export rates that generate
foreign exchange not only for the industries but also for the country as a whole increase.

Keywords: Beef cattle, animal welfare, quality of meat

\section{Sacrificio de ganado: Consideraciones sobre el sacrificio humanitario y la sangría cruenta}

RESUMEN. Métodos convencionales, como el sacrificio humanitario, utilizan la insensibilización antes de la sangría para que los animales sean abatidos sin sufrimientos y 
para que la sangría sea más eficiente. Los sacrificios que se efectúan conforme los rituales religiosos, judíos o musulmanes, utilizan el corte de la garganta del animal. Este trabajo fue desarrollado con el objetivo de resaltar la diferencia entre el sacrificio humanitario y el sacrificio cruento, aclarando cada método de sacrificio utilizado, como funciona la línea de sacrificio, qué animales pueden ser utilizados y cómo los frigoríficos logran los certificados. El sacrificio humanitario y el sacrificio cruento son métodos diferentes, cada uno con su particularidad, pero que tienen el mismo objetivo que es garantizar el bienestar animal y obtener carne de calidad para sus determinados consumidores. El tema se hace de gran relevancia ya que Brasil tiene un interés económico en los sacrificios religiosos, y debido al valor agregado en las negociaciones, se aumentan las tasas de exportaciones que generan divisas no sólo para las industrias, sino también para el país en su conjunto.

Palabras clave: Ganado vacuno, bienestar animal, calidad de la carne

\section{Introdução}

No Brasil no decorrer dos últimos anos houve aumento no número do rebanho bovino, chegando a 212,3 milhões de cabeças em 2014, sendo abatidos no de 2015, 7,74 milhões de cabeças. No $1^{\circ}$ semestre de 2016 houve uma queda de 5,8\% totalizando 7,29 cabeças, segundo o $\underline{\operatorname{IBGE}(2016)}$. No centro-oeste, está localizada a principal região produtora com $33,5 \%$ do gado bovino nacional (BRASIL, 2016).

Houve um aumento da demanda do mercado consumidor externo e interno de carne bovina e como consequência teve o crescimento do rebanho. O mercado consumidor mundial, cada vez mais preocupado com o bem-estar animal impulsionou muitos países, incluindo o Brasil, a adotar legislações que exigem técnicas de abate humanitárias e de padrões de qualidade.

Métodos convencionais, como o abate humanitário, utilizam a insensibilização antes da sangria para que os animais sejam abatidos sem sofrimentos desnecessários e para que a sangria seja mais eficiente. Já os abates que são efetuados conforme os rituais religiosos, judaicos ou muçulmanos, utilizam a jugulação cruenta (Cortesi, 1994), que é a degola dos animais com corte de uma só vez da pele, músculos, traquéia, esôfago, jugulares e carótidas, sem atordoamento prévio. Esses abates são conhecidos como Kosher (Judaicos) e Halal (Islâmicos). Ambos têm suas leis religiosas determinadas pelos livros sagrados Torá (Kosher) e o Alcorão (Halal). O abate religioso é um dos mais lucrativos para exportação, principalmente no Brasil (Bonfim, 2003). Conforme a Instrução Normativa $\mathrm{N}^{\circ} 3$ de 17/01/2000 do MAPA é facultado o sacrifício de animais de acordo com os preceitos religiosos, desde que sejam destinados ao consumo da comunidade religiosa (BRASIL, 2000).
Segundo Cortesi (1994), o processo de abate possui algumas etapas que são de grande importância como o transporte, descanso, movimentação nos currais de espera, insensibilização e sangria. Por isso, é necessário que seja feito treinamento e capacitação dos magarefes, que são pessoas designadas a abater os animais. No caso do abate religioso Kosher, uma pessoa específica e treinada para realizar este tipo de abate é denominada de Shochet.

Os métodos de abate humanitário e jugulação cruenta vão se diferenciar principalmente em relação à insensibilização, ao tempo e técnicas durante as operações de abate, quantidade de animais abatidos por dia, ferramentas utilizadas no abate e a eficiência da sangria, assuntos que serão discutidos no decorrer do trabalho.

Este trabalho foi desenvolvido com o objetivo de salientar a diferença entre o abate humanitário e a jugulação cruenta, esclarecendo cada método de abate utilizado, como funciona a linha de abate, quais animais podem ser utilizados e como os frigoríficos conseguem os certificados.

\section{Abate Humanitário}

O abate humanitário tem como objetivo garantir o bem-estar dos animais desde o embarque na propriedade até a sangria no frigorífico. Segundo a Instrução Normativa $\mathrm{N}^{\circ} 3$ de 17/01/2000 do MAPA, o abate humanitário pode ser definido como o conjunto de procedimentos técnicos e científicos que garantem o bem-estar dos animais desde o embarque no estabelecimento rural até a operação de sangria na indústria frigorífica (BRASIL, 2000). Os pontos utilizados no abate humanitário e bem-estar animal no pré-abate serão o transporte e desembarque dos animais, descanso, jejum e dieta hídrica, instalações (banho de aspersão), insensibilização e sangria. 
A Instrução Normativa $N^{\circ} 56$ de 06/11/2008, que trata do REBEM (Regulamento Técnico de Método de Insensibilização para o abate humanitário de animais de açougue), afirma que o manejo deve ser cuidadoso e responsável nas várias etapas de vida do animal; que as pessoas responsáveis tenham conhecimentos básicos do comportamento animal e que os animais sejam manejados e transportados de forma adequada para reduzir o estresse evitando sofrimento e contusões desnecessárias (BRASIL, 2008).

\section{Embarque, transporte e desembarque}

O primeiro passo para o embarque dos animais começa dentro do escritório da fazenda verificando se todos os documentos necessários estão corretamente preenchidos. Os animais devem ser conduzidos para o curral sem correria e sem gritos. No curral ocorre a separação e formação de lotes para o embarque, proporcionais à capacidade de carga de cada um dos compartimentos do caminhão. Após a formação cada grupo, são levados ao embarcador para ter acesso ao veículo (Costa, 2013).

O transporte de animais no Brasil acontece predominantemente por meio rodoviário e necessita de vários documentos como os documentos do veículo, a carteira de habilitação do motorista, guia de transporte de animais e certificados sanitários em alguns casos (Costa, $\underline{2013}$ ).

Os veículos utilizados podem ser "caminhões boiadeiros", medindo 10,60 x 2,40 metros, com capacidade de carga de 20 animais, caminhão truck, carreta e veículo duplo- articulado conhecido como bi-trem, compostos por dois compartimentos de cargas independentes, ambos com piso, tendo um maior cuidado e atenção quando os animais forem acessar a rampa do segundo compartimento ( $\underline{\text { Costa, 2010)}}$.

Os caminhões mais modernos possuem as laterais e a parte traseira dos compartimentos semivedados, sendo recomendado deixar uma abertura de $40 \mathrm{~cm}$ no piso do compartimento, utilizar telas de sombreamento e parar os veículos em locais sombreados, pois a vedação pode atrapalhar a ventilação e monitoramento. Veículos assim fazem com que os animais fiquem menos estressados por estímulos externos e tenham redução de fezes e urinas nas estradas. O piso dos compartimentos deve ser coberto por um tapete de borracha e uma grade de ferro quadriculada proporcionando conforto e segurança, diminuindo os efeitos negativos como escorregões e quedas. Os compartimentos devem estar em bom estado de conservação necessitando de manutenção, limpeza e desinfecção (Costa, 2010).

Mesmo a taxa de mortalidade de bovinos no transporte sendo baixa, esta continua sendo a fase mais delicada do pré-abate devido ao estresse, que pode acabar errando comprometimento da carcaça como traumatismos, aumento dos níveis de cortisol e hematomas, podendo afetar o peso da carcaça e o destino final, além de resultar em coloração inadequada. Animais com maior peso e mais jovens tendem a ser menos resistentes no transporte comparado com animais mais leves e adultos (Knowles, 1999; Thornton, 1969). Devido a isso é importante observar a densidade dos animais nos veículos, pois a densidade maior que $550 \mathrm{~kg} / \mathrm{m}^{2}$ é inapropriada (Tarrant, et al. 1992).

O motorista, no momento do embarque, deve orientar as pessoas encarregadas para executar um manejo adequado. Ao dar início à viagem deve conhecer a rota e fazer o monitoramento, começar o percurso devagar tendo cuidado para que todos os animais se mantenham em pé. $\mathrm{O}$ monitoramento dos animais é obrigatório durante a viagem, principalmente em estradas em más condições, devendo dirigir com cuidado e atenção, evitando o desequilíbrio e queda dos animais, pois estes podem ser pisoteados pelos demais aumentando a possibilidade de contusões. Em casos de animais deitados, antes de levantá-los o motorista deve observar se há espaço suficiente e se o animal está na posição certa, ou se há alguma fratura que dificulte o animal erguer (Costa, 2010).

Ciocca, et al. (2006), analisaram o valor do pH da carne (Figura 1) e a quantidade de hematomas (Figura 2) em animais Nelore e cruzados, antes e após o treinamento dos motoristas.Concluíram que o treinamento dos motoristas no momento do embarque, na condução do veículo e no desembarque auxiliou na redução do $\mathrm{pH}$ da carne e dos hematomas. 


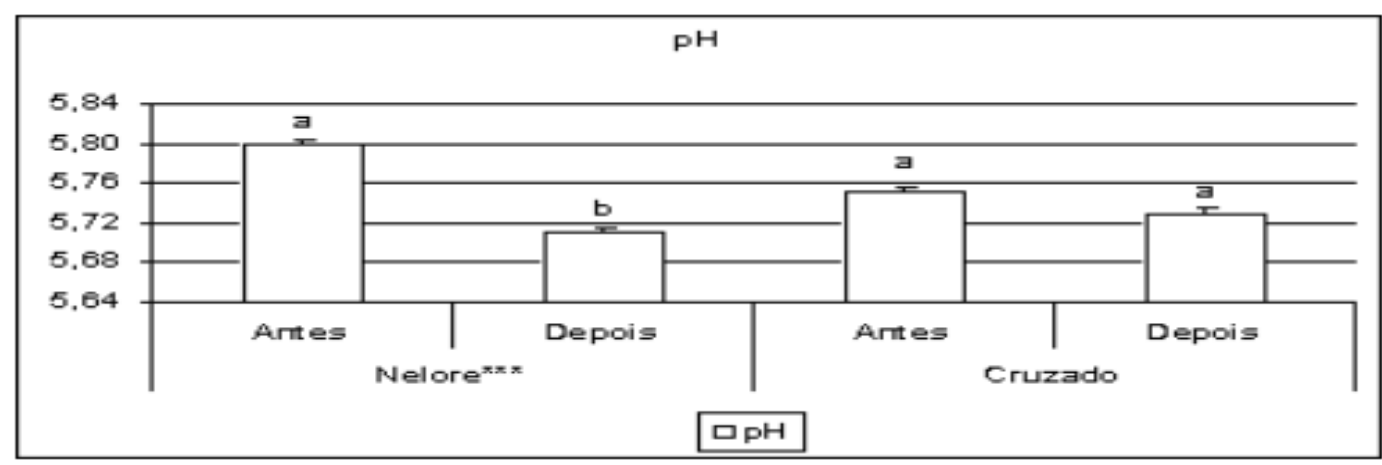

Figura 1. Valores de $\mathrm{pH}$ da carne bovina antes e após treinamento dos motoristas. Letras diferentes no mesmo grupo genético diferem estatisticamente entre si pelo teste de Tukey.

Fonte: Ciocca, et al. (2006).

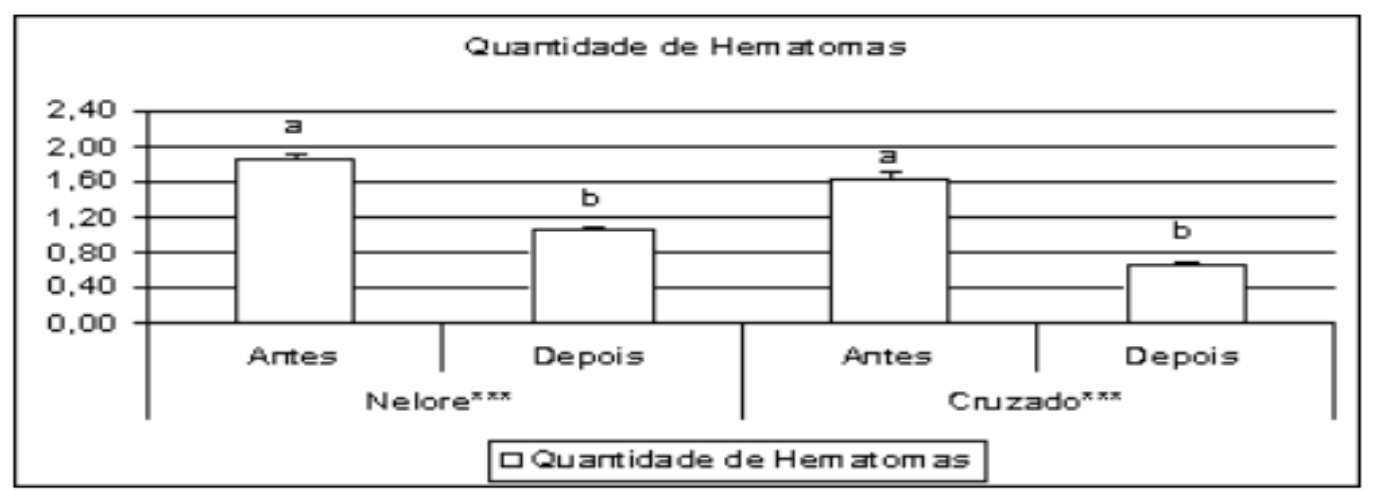

Figura 2. Quantidades de hematomas antes a após treinamento dos motoristas. Letras diferentes no mesmo grupo genético diferem estatisticamente entre si pelo testede Tukey.Fonte: Ciocca, et al., (2006).

No desembarque deve haver uma área externa sombreada para os caminhões que ficarem em espera e o tempo de permanência nesta área não deve ultrapassar 10 minutos. Antes do desembarque o motorista deve fazer o último monitoramento verificando se tem algum animal deitado. Feito isso, a porteira deve ser aberta para que os animais tenham acesso à rampa de desembarque, sendo formada por um ângulo inferior a $20^{\circ}$, podendo ser utilizada uma bandeira para estimular a saída. No momento do desembarque devem ser evitados equipamentos que causam traumas, forçando a descida, podendo causa fraturas ou hematomas. Em situações que o animal esteja ferido ou muito debilitado e não consegue se levantar é necessário realizar o abate de emergência (Costa, 2010).

\section{Descanso, Jejum e Dieta hídrica}

Após os animais serem transportados e desembarcados, que é um período bem estressante, eles são conduzidos para uma área de descanso que são os currais de chegada, seleção e currais de matança, proporcionando a recuperação do estresse.
O período de descanso, jejum e dieta hídrica é o tempo necessário para a recuperação das perturbações surgidas pelo transporte, tendo como objetivo evitar a contaminação das carcaças, pois resulta em diminuição do conteúdo gastrointestinal facilitando a evisceração e auxilia no momento da sangria. Ameniza o estresse por calor, proporciona hidratação e permite $\mathrm{o}$ restabelecimento das reservas de glicogênio muscular (BRASIL, 1952; DIPOA, 2017).

Conforme o artigo $\mathrm{n}^{\circ} 110$ do RIISPOA (Regulamento de Inspeção Industrial e Sanitário de Produtos de Origem Animal), os animais devem permanecer nos currais em descanso, jejum e dieta hídrica por 24 horas. Este período poderá ser reduzido dependendo da distância da propriedade até o frigorífico, quando o tempo de viagem não for superior a duas horas. Entretanto, o repouso não deve ser inferior a seis horas.

Durante este período ocorre a inspeção antemortem, com a finalidade de conferir os certificados de vacinação e a sanidade do rebanho, visualizar e isolar aqueles animais que estão debilitados ou doentes, vacas em estado avançado de gestação ou recém paridas e o controle da 
higiene dos currais e anexos, como bebedouros. Os animais enfermos serão conduzidos ao curral de observação e deverão ser abatidos separadamente dos demais no matadouro sanitário ou abatidos por último na sala de matança (Snijders, 1989).

São cinco as causas que afetam o bem-estar animal antes de serem abatidos: funcionários não capacitados, estresse por contato com equipamentos que podem provocar contusões, mistura de lotes com animais de locais diferentes que acabam brigando por liderança, manejo inadequado das instalações como a conservação de pisos e corredores, e a movimentação do animal, como brincar com objetos de metais que brilham, reflexo da água no piso e ruídos (Grandin, 2012).

Frigoríficos que exportam para a União Europeia devem atender as regras do Regulamento da CE 1099 (Parlamento Europeu e do Conselho), onde o tempo de permanência é de 12 horas no curral de espera. Os animais vão necessitar de espaço no mínimo em área de currais de $2,5 \mathrm{~m}^{2}$ por animal, para efetuar movimentos normais como deitar, levantar, andar, entre outros (DIPOA, 2017).

\section{Banho de aspersão}

Quando chega à hora do abate, os animais que estavam nos currais em descanso, jejum e dieta hídrica são conduzidos para o banho de aspersão. $\mathrm{O}$ banheiro deve conter um sistema tubular de chuveiros dispostos longitudinal, transversal e lateralmente direcionando os jatos para o centro do corredor. A água deve possuir pressão de 3 atmosferas e com hipercloração de até 15 ppm de cloro (BRASIL, 2016).

O banho de aspersão retira as sujeiras da pele dos animais antes do abate reduzindo a contaminação do ar na sala do abate. Também ocorre à limpeza dos cascos, extremidades e região anal. É recomendável que os animais permaneçam na rampa de acesso por alguns minutos para secar a pele, pois não deve esfolar animais úmidos. Deve ser evitado que ocorram quedas e fraturas, por isso é de grande importância o controle do piso para que não seja escorregadio (Steiner, 1983).

Roça e Serrano (1995) analisaram se o banho de aspersão antes do abate influenciava algum parâmetro da qualidade da carne, como modificações bioquímicas e bacterianas do músculo Longissimus dorsi (porção caudal) e as contaminações da superfície da carcaça ao longo da linha do abate. Concluíram que o banho de aspersão não apresentou efeito nas contagens de bactérias da porção interna do músculo, mas apresentou esfola mais higiênica, evitando o contato direto da pele com a superfície da carcaça.

\section{Insensibilização}

Após o banho de aspersão os animais são conduzidos para o box de insensibilização ou atordoamento. $\mathrm{O}$ box será composto por uma plataforma para o operador, uma comporta para a entrada do animal e uma lateral para a saída. O animal ficará imobilizado para permitir o correto manejo da pistola que irá colocá-lo em um estado de inconsciência, mantendo suas funções vitais, sem causar sofrimento, até a sangria (Infante, $\underline{2000)}$.

O animal será colocado em um box composto por uma estrutura metálica que irá contê-lo totalmente. Nesse processo as laterais do animal são imobilizadas por uma parede móvel, que na região do trapézio recebe o nome de pescoceira. Abaixo da cabeça do animal se eleva uma bandeja para que seja efetuada da melhor maneira a insensibilização, oferecendo melhor segurança ao operador de abate (Gomide et al., 2006).

Os métodos de insensibilização que podem ser utilizados classificam-se em: método mecânico (percussivo não penetrativo e percussivo penetrativo), método elétrico com a eletronarcose e método da exposição à atmosfera controlada (câmara de gás carbônica).

A insensibilização não penetrativa causa uma lesão de concussão cerebral, ocorre um distúrbio no cérebro de curta duração e não perfura o crânio. A perda da consciência ocorrerá em decorrência de uma hemorragia cerebral, formação de vacúolos no encéfalo, pressão no mesencéfalo e bloqueio do fluxo sanguíneo, por conta da pressão intracraniana (Bannister, 1992; Gracey, 2000; Ommaya, 1971). Já a pistola de dardo cativo penetrativa acarreta uma pressão maior e causa uma disfunção da atividade elétrica, tendo uma imediata perda de consciência. O dardo destrói o tecido cerebral, pois no seu trajeto lesiona a superfície do crânio. Este é o método mais utilizado no Brasil (Gregory, 1998; Roça, 2002; Finnie, 1993).

Lambooy et al. (1981) constataram em seu trabalho que a pistola de dardo penetrativa é bem mais eficiente em comparação à não penetrativa. Demonstraram que apenas $50 \%$ dos animais que 
foram atordoados com a pistola de dardo não penetrativa estavam insensibilizados de forma correta.

A forma correta de disparo para a insensibilização pelas pistolas pneumáticas é no plano frontal da cabeça do animal, na interseção de duas linhas imaginárias que começa na base do chifre até o olho do lado oposto da cabeça do animal (Figura 3). O dardo penetra com alta velocidade, em média de 100 a $300 \mathrm{~m} / \mathrm{s}$, com força de $50 \mathrm{~kg} / \mathrm{mm}^{2}$ (Roça, 2001). A posição recomendada de aplicação do golpe com a pistola não penetrativa, dois $\mathrm{cm}$ acima do local indicado no penetrativo, porém há risco da insensibilização ser mal feita ou o animal retomara consciência mais rapidamente (Gregory, 2007).

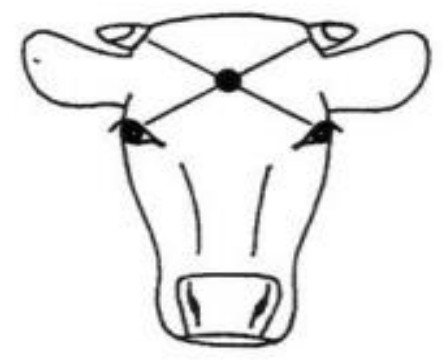

Figura 3. Posição correta para o disparo na cabeça do bovino. Fonte: (Neves, 2008).

Para ter uma eficiência na insensibilização o operador deve ter atenção na angulação da pistola, ter funcionários treinados, manutenção e uso correto dos equipamentos e contenção correta dos animais.

Quando essas normas são respeitadas é possível atender às exigências de bem-estar animal. Os animais devem perder a consciência imediatamente e ser observados alguns reflexos como: entrar em colapso e não mostrar nenhum sinal de respiração rítmica, mandíbula inferior relaxada, cabeça estendida e posição do globo ocular fixa, sem reflexo corneal, batimentos cardíacos, língua para fora da boca com os músculos relaxados e podem ter movimento de pedaladas (Renner, 2006).

Grandin (1999) descreveu que um animal bem insensibilizado apresenta um colapso, caindo no chão imediatamente após o disparo. Depois começa a fase clônica da convulsão cerebral, ocorrendo à flexão e enrijecimento dos membros com duração de 15 a 20 segundos. Em seguida tem-se a fase tônica, que são movimentos de pedalagem. $\mathrm{O}$ animal deve apresentar o pescoço relaxado e olhar fixo e vidrado, em aproximadamente 20 segundos.

\section{Sangria}

A sangria deve ser iniciada no máximo um minuto após a insensibilização, de modo a provocar um rápido e completo escoamento do sangue, antes que o animal recobre a sensibilização. Neste processo ocorre à secção dos grandes vasos do pescoço. São utilizadas duas facas na sangria, uma para o corte dos vasos do pescoço e a outra para a abertura da barbela, devendo ser esterilizadas a cada animal que for cortado (FAO, 2001).

O sangue deve ser recolhido por meio da canaleta de sangria e os animais devem permanecer sangrando içados na trilagem aérea por no mínimo três minutos. Durante este período, nenhuma operação da esfola pode ser realizada. $\mathrm{O}$ sangue vai ter aproveitamento industrial principalmente para a fabricação de farinha de sangue. Também pode ser utilizado como comestíveis e, para isso, são utilizadas facas especiais (Faca Vampiro) que se conectam diretamente nas artérias, sendo o sangue colocado em recipientes esterilizados. $\mathrm{O}$ volume de sangue de bovinos é de 6,4 a 8,2 litros/100kg de peso vivo. Quando se tem uma eficiente sangria é removido em média de $60 \%$ do volume total de sangue sendo o restante de músculos (10\%) e vísceras (20-25\%). A sangria feita o mais rápido possível após o atordoamento vai fazer com que o volume de sangue removido seja maior (Hedrick, 1994; Swatland, 2000).

\section{Jugulação cruenta}

A jugulação cruenta é a degola do animal sem insensibilização prévia para atender preceitos religiosos. Utiliza- se uma faca bem afiada, o corte atinge a traquéia, esôfago, veias jugulares e artérias carótidas. Este método de abate tem sido um tema bastante discutido e criticado por conta do bem-estar animal, pois não há insensibilização (Europa, 2004).

Grandin (1997) descreveu que com a utilização da jugulação cruenta é possível proporcionar o bem-estar animal utilizando de forma correta o box de atordoamento, eliminando pisos escorregadios e não utilizando choques. A faca utilizada deve estar sem defeitos e bem afiada para ter um corte eficiente e rápido, seccionando todos os vasos do pescoço de uma só vez. 
No Brasil, a Instrução Normativa $\mathrm{N}^{\circ} 3$ prioriza a utilização da insensibilização antes do abate, mas é opcional o uso da jugulação cruenta para animais desde que sejam destinados à comunidades religiosas ou exigência comercial entre os países. O Irã é um exemplo, já que nos contratos com o país se cobra a presença de um médico veterinário Islâmico vistoriando a qualidade da carne e de um Sheikh, que é um líder religioso. Assim sendo, os frigoríficos têm se especializado cada vez mais para atender as

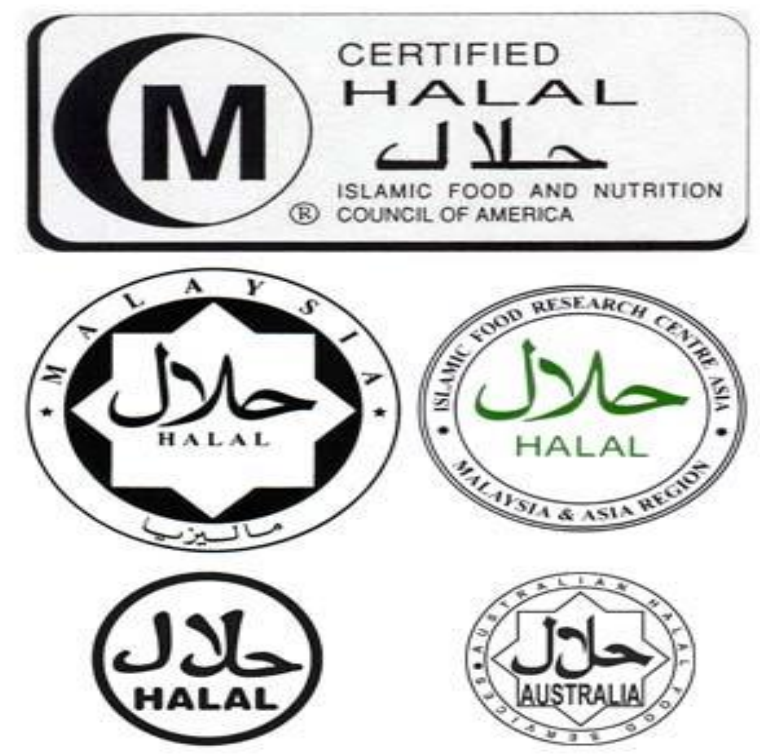

Figura 4. Símbolos de certificação. Fonte: Kosher beijing (s/a).

\section{Kosher}

O termo hebraico Kosher ou Kasher tem como significado "bom" e "próprio", é a definição dada aos alimentos preparados segundo as leis judaicas de alimentação, nomeadas como Kashrut tendo origem no Torá ou Livro Sagrado e no Tamulde, que determinam as restrições alimentares, como por exemplo, quais animais são puros, proibição do consumo de misturas de carne com leite, o consumo de sangue e a proibição de cortes do quarto traseiro.

O abate Kosher não é permitido em países como a Suíça, Noruega, Suécia e Países Baixos em animais conscientes (Levinger, 1995). Atualmente, na África do Sul, o regulamento permite o abate por meio do método Kosher, desde que os animais sejam atordoados anteriormente (20 segundos) da degola.

Existem duas explicações em relação às leis judaicas referentes aos hábitos alimentares. Uma afirma que esse tipo de alimentação foi estabelecido para garantir a saúde do povo, exigências desse mercado procurando expandir a comercialização.

Os dois tipos de abates religiosos realizados no Brasil são o Kosher que segue o Torá e o Halal que segue o livro sagrado Alcorão. As carnes dos animais abatidos por alguma dessas formas recebem certificados de que todos os produtos seguiram as leis religiosas (Figura 4), sendo atribuído como sinônimo de controle de qualidade.

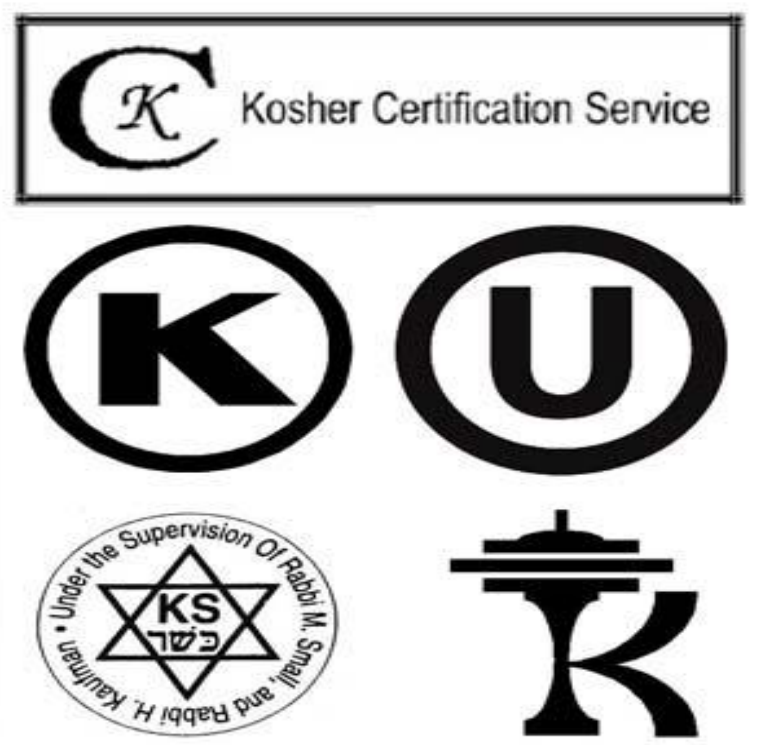

ingerindo somente animais puros livres de qualquer doença. A outra determina que a única razão para ter esses hábitos está na bíblia. Essas leis fizeram com que os judeus se unissem e tinham em mente que eram povos diferentes das outras nações.

Os alimentos Kosher representam nos Estados Unidos um mercado de US\$ 35 bilhões/ano, produzidos por 9.600 empresas do ramo de alimentação e 16.000 empresas que vendem o produto certificado. No Brasil vivem cerca de 180 mil judeus, sendo 120 mil só em São Paulo, necessitando de um investimento mais amplo em empresas que vendem produtos com o certificado Kosher (Barreto and Castro, 2004).

\section{Conceitos relacionados ao abate Kosher}

\section{-Leis de Shechitá}

Shechitá é o ritual religioso judaico de abate, o único utilizado para a produção de carne Kosher. Seguindo os princípios da fé judaica conforme o Torá, assegurando uma morte rápida e indolor dos 
animais, infringir as leis torna a carne imprópria para alimentação. O procedimentoé realizado por um Shochet, que significa "abatedor de ritual", um judeu treinado especificadamente para executar o ritual e inspeção das carcaças (Codignoli, 2003).

\section{- Shochet}

O Shochet irá utilizar um objeto cortante a Chalaf, uma faca que deve ser lisa e sem irregularidades, para efetuar a degola com corte eficiente de forma rápida das artérias carótidas e veias jugulares, traquéia e esôfago sem atingir as vértebras cervicais. Segundo Pichhi and Ajental (1993), 95\% dos animais que passavam por uma degola rápida chegavam à inconsciência no intervalo de dois segundos. Para ter esse efeito é necessário bom treinamento do Shochet e boa qualidade da Chalaf. Um golpe mais lento ou mal feito pode acarretar sofrimento e os animais vão manter os reflexos sensoriais por 30 segundos (Baruch, 2008).

Há cinco parâmetros que o Shochet é obrigado a assegurar no exercício da Shechitá:

1. Shehiya: não deve haver a mínima pausa durante o processo de Shechitá;

2. Derassa: O processo de abate deve ser efetuado com o movimento da faca de um lado para o outro. A faca deve ser bastante longa para permitir matar sem muita pressão. Além disso, o animal deve estar em uma posição que suaviza a pressão que será colocado na faca;

3. Chalada: A faca para Shechitá deve ter uma lâmina longa e larga sem dente na frente ou no dorso, também a faca deve estar descoberta durante $o$ abate;

4. Hagrama: O corte deve ser realizado na garganta, entre o nível da laringe e a parte mais baixa da traquéia e esôfago;

5. Ikkur: A traquéia e esôfago devemser cortados e não arrancados. Por isso, a faca deve ser muito bem afiada e lisa. Os menores dentes no fio causam rasgos. Por isto, é feita a verificação da faca quanto à rugosidade do fio e sua afiação depois de cada Shechitá.

\section{-Chalaf}

Uma lâmina retangular sem curva. Sendo utilizada para a degola, tendo comprimento de 41 $\mathrm{cm}$ e largura de $4-5 \mathrm{~cm}$. Recentemente essas facas são produzidas em grande quantidade, pois antigamente eram passadas de geração pra geração sendo mais admiradas e utilizadas. Devem ser afiadas manualmente em pedras e ser resistentes. Um profissional consegue sacrificar, em uma hora, em torno de 60 cabeças. O tempo de trabalho dura em média 5 horas por dia (Bonfim, 2005).

Na degola, o animal é encaminhado para o box de insensibilização, sendo exposta uma das patas traseiras, presa por uma corrente com carretilha. Após o box ser aberto, a corrente é suspensa por um guincho mantendo o posterior do animal suspenso e abaixado seu dorso até encostar no solo. Sobre a mandíbula é colocado um gancho que pressiona o pescoço. O Shochet deve examinar a lâmina antes e depois da degola na unha, pois caso tenha algum arranhão ou dente no fio da faca após a degola, o animal é considerado como não Kosher, ou seja, impróprio para o consumo dos judeus, seguindo para a canaleta de sangria e esfola.

Por motivos de segurança e humanitárias, os frigoríficos que realizam o abate Kosher devem instalar equipamentos modernos eliminando as práticas de suspender os bovinos. A substituição do box resulta na redução de $50 \%$ dos acidentes. O aparelho de contenção indicado pela American Society for the Prevention of Cruelty to Animals (ASPCA) é constituído por um box estreito com abertura para a cabeça do animal. Após a entrada no Box o animal é empurrado para frente por um portão e em seguida sob o peito é encostado um elevador de barriga, sendo restrito a $71 \mathrm{~cm}$. A cabeça é contida pelo levantador facial para facilitar a degola feita pelo Shochet. É necessário ter uma barreira sólida na frente bloqueando a visão do animal. $\mathrm{O}$ operador deve evitar movimentos ríspidos, mantendo o animal quieto. Tem capacidade máxima de 100 cabeças por hora, mas tem uma melhor eficiência com 75 cabeças por hora (Grandim, 2010).

No ritual de Shechitá, após a degola é feita uma prece especial denominada Beracha, que em hebraico tem significado de "benção". O Shochet deverá realizar a benção dizendo "Que nos santificou com seus mandamentos e nos ordenou sobre o abate ritual". Se houver diversos animais para abater basta uma benção, desde que o Shochet os tenha em mente na hora de realizar a benção (Baruch, 2008).

\section{- Treifos}

De acordo com os judeus, um animal impróprio para consumo é baseado no que eles chamam de Trefa, que significa rasgada. Conforme a história, 
Moisés foi comandado a verificar em Sinai oito itens de injúria mortal, que diferenciam os animais puros dos impuros, ou seja, animais que tiveram substâncias venenosas introduzidas no corpo por um animal de presa, paredes de um órgão perfuradas, faltando órgãos, traumatismo por queda, veias rompidas e fratura em ossos, se tornam animais impuros dispensáveis, pois não são considerados Kosher. Caso ocorra a degola desses animais, o sangue deve ser coberto por areia ou terra, por não ser um sangue puro (Eliasi, and Dwyer, 2002)

Após a sangria tem continuidade o ritual judaico, sendo os órgãos internos inspecionados, denominado como Bedicá, por um inspetor treinado, conhecido como Bodek. Para verificar qualquer anomalia podendo tornar o animal não Kosher (treif), os pulmões são palpados pelo Judeu para verificação de aderência enquanto ainda não foram eviscerados. Um segundo Judeu irá utilizar um compressor na traquéia inflando os pulmões, buscando confirmar a presença ou não dessa aderência. Caso tenha alguma fissura nos pulmões o animal e desclassificado, garantido um padrão de qualidade.

\section{- Animais Puros e Impuros}

Os animais devem ser ruminantes, apresentarem cascos fendidos em duas partes, como por exemplo, bovinos, caprinos e ovinos. Pois, segundo a crença do ritual judaico, Deus criou esses animais de maneira especial. Alguns animais possuem casco fendido, mas não atendem todos os requisitos, sendo eles impuros como o porco, o coelho, o camelo e a lebre.

\section{- Carne GlattKosher}

Glatt significa "suavizar", indicando que a carne é proveniente de um animal que passou por uma inspeção e está livre de todas as aderências nos pulmões. O termo é usado como garantia de que o produto é Kosher (Kosherandhalal, 1984).

\section{- Nikkur}

O procedimento de corte que tem como significado hebraico "extirpar", deve ser realizado por alguém treinado. $\mathrm{O}$ corte vai ser a retirada das veias, vasos sanguíneos, nervos, tendões e da capa de gordura (hebraico, Chelev) que são proibidas de ser ingeridas.

No processo chamado de Koshering ou Meicha a carne deve ser colocada em imersão em água e sal para que haja a máxima retirada de sangue.

\section{- Salga e grelha}

Somente as carnes de animais puros vão passar por este processo, a carne deve ficar imersa a água fria por meia hora, retira-se o excesso de água e cobre com uma camada de sal grosso, deixada por uma hora em uma superfície inclinada permitindo que o sangue flua e depois deve ser lavada para remoção do sal. A carne deve ser Koshering (retirado o sangue) dentro de 72 horas após o abate para que o sangue não coagule. A grelha é um método alternativo, o fígado pode apenas passar por esse processo para ser considerado uma carne Kosher. Tanto a carne quanto o fígado devem ser lavados para a remoção do sangue e em seguida salgados, são feitas fendas no fígado, pois o fogo liberará o sangue, após a grelha a carne ou o fígado são enxaguados.

\section{- Nervo ciático}

Não deve ser ingerido em virtude de uma passagem bíblica, em que Jacob luta com um estrangeiro misterioso e acaba ferido na parte do corpo que tem o nervo ciático e fica manco. Jacob era o patriarca do judaísmo, e por isso, foi proibido o consumo do nervo ciático, consequentemente do quarto traseiro dos animais onde está localizado este nervo. O processo de remoção é demorado e não é rentável para os frigoríficos. Na América do Norte e do Sul o quarto traseiro é vendido para uso de carne não Kosher (Bitencourt, 2001).

As partes do animal consumidas pelos judeus são o dianteiro completo, sendo eles o peito, acém, paleta, capa de filé e músculos Kosher. A carcaça do animal é cerrada entre a nona e a décima vértebra torácica. Os miúdos como o pulmão, língua, porções de carne retiradas da cabeça e os tendões dianteiro e traseiro também são considerados carne, mas devem passar por um processo de salmoura por meia hora, para assim serem embalado e congelado para a exportação (BRASIL, 2016).

\section{Certificado Kosher}

Uma equipe de Judeus faz uma visita ao frigorífico analisando todo o processo de fabricação e os ingredientes contidos nos produtos usados no abate, garantindo que todas as exigências dos livros sagrados foram atendidas. $\mathrm{O}$ certificado é emitido por um determinado período de tempo e volume de carne. O frigorífico deve procurar ter uma relação de nitidez com os Judeus para evitar a invalidação do certificado. Entre os diversos produtos processados Kosher, 
encontram-se o salsichão bovino, fiambre bovino com vegetais, língua bovina defumada, vitela bovina e carpaccio bovino. É comum visualizar em embalagens símbolos certificando que o alimento é Kosher. Estes símbolos são referentes às organizações judaicas que certificam que o alimento foi preparado de acordo com a tradição do judaísmo. A comida Kosher possui maior valor que as não Kosher, pois existe um custo extra no ritual da morte e na inspeção do produto. As empresas brasileiras que recebem esse certificado são o JBS, Marfrig,Minerva e Frisa, dependendo da unidade (Barreto and Castro, 2004).

Segundo a Associação Brasileira de Indústrias Exportadoras de Carne (ABIEC), no ano de 2013 o Brasil exportou 348.973 toneladas de carne Kosher para o Oriente Médio e norte da África, sendo que a cada ano vem aumentando ainda mais a exportação (BRASIL, 2015). O Brasil está de olho nesse nicho de mercado, e um importante comprador é Israel. Segundo o Ministry of Economy and Industry, as exportações brasileiras para Israel fecharam em US\$ 380 milhões, o faturamento que o Brasil teve com a exportação pra Israel em dezembro de 2015 foi em torno de US\$ 12.000.000,00. Os alimentos Kosher não interessam somente aos judeus, também podem alcançar o mercado mulçumano e cristão, pois as leis dietéticas judaicas são mais rigorosas que as demais (BRASIL, 2015).

\section{Halal}

Halal é um termo árabe que significa lícito, permissível. Seguindo as leis religiosas impostas pelo Alcorão (escrita muçulmana) e pela Jurisprudência Islâmica no contexto de produtos alimentares, em nome de Allah (Deus). As regras alimentares são denominadas como Shariah/ Zabihah que significa caminho, de acordo com as exigências dos países islâmicos, o abate Halal deve ser realizado separado do não Halal. Os alimentos que são considerados como proibidos são denominados como Haram e os alimentos que tem sua origem duvidosa ou questionável, são considerados alimentos Mashbooh (Gomide, $\underline{2006}$ ).

O motivo dos muçulmanos seguirem as regras islâmicas não é somente por motivos religiosos. Os consumidores se preocupam também com a saúde, a higiene, uso do ambiente e o respeito ao bem-estar animal. Por isso, todo o processamento, o preparo, o armazenamento e transporte devem ser específicos para os produtos Halal.

\section{Normas de abate Halal}

$\mathrm{O}$ abate Halal em árabe é conhecido como Mazbah, os animais permitidos para este abate seguem a mesma linha de pensamento que os judeus, sendo animais de casco fendido e ruminantes. Devem ser executados por um muçulmano sadio, treinado e que conheça os fundamentos das leis islâmicas, conduzindo de forma mais humanizada, evitando sofrimento dos animais, que devem estar em perfeita condição física. O objetivo do ritual é proporcionar uma rápida insensibilidade e inconsciência no animal vivo, permitindo uma maior eliminação de sangue. Os países mais modernos permitem o atordoamento antes da degola dos animais desde que essa insensibilização seja reversível, como exemplo a pistola de dardo cativo não penetrativa. O emprego da insensibilização permite maior velocidade de abate (Keynes, 2001).

No momento da degola o animal deve estar com a face virada para a Meka e ser abençoado em nome de Allah. O muçulmano que executa a degola é conhecido como Zabeh. Deve proferir a benção conhecida como Tasmiya ou Sahada,"Em nome de Deus, o clemente, o misericordioso / BESS.EL.AL" para cada animal antes de seu sacrifício.O Zabeh tem menos de um minuto para degolar cada animal. A faca utilizada deve ser de aço, ser bem afiada a cada degola e não é permitido que outros animais vejam a faca antes de serem abatidos ou verem outrosanimais sendo abatido. A água deve ser oferecida antes do abate e não devem ser abatidos animais com fome (Keynes, 2001).

No método Halal será aproveitada a parte do dianteiro e traseiro do animal, diferente do abate Kosher. As partes do animal que não devem ser consumidas mesmo se forem abatido de acordo com as regras islâmicas são os órgãos reprodutivos, nervos, hipófise, medula espinhal, glândulas, placenta e cordão umbilical, vesícula biliar, íris, quimo, ossos, pele e pelo. No abate Halal não possui uma inspeção específica de cavidade torácica como no Kosher.

A carne deve ser armazenada refrigerada ou congelada separada de outras carnes não Halal. A exigência de tipo de resfriamento vai depender do país e são exportados cortes separados. Carnes Halal não devem ser picadas ou processadas na mesma máquina utilizada para picar carnes de porco ou carnes não Hallal (Khattak, 2011). 


\section{Alimentos proibidos (Haram)}

São proibidos alimentos como carnes de porco e produtos, como bacon, banha de porco, presuntos e linguiças, por serem consideradas carnes imundas e impuras, pois os animais vivem em um espaço de imundice; Sangue fresco ou coagulado, pois contém organismos causadores de várias doenças. Por isto, o abate dever ser eficaz drenando todo o sangue. Carnes de bovinos que foram alimentados com subprodutos ou com alimentos de origem Haram, como por exemplo, alimentos de origem animal.

No caso do Brasil é proibida a utilização destes alimentos na dieta de bovinos. Alimentos que tiveram contato direto ou que contém substâncias ilícitas; Carnes de animais que não foram abatidos conforme as leis Islâmicas; Animais abatidos em nome de outros que não seja Allah; Produtos que contêm gelatina, pois são feitos das partes proibidas dos animais, chifre e cascos; Animais modificados geneticamente, o próprio frigorífico no momento da compra não aceita animais modificados (Khattak, 2011).

\section{Certificação e mercado Halal no Brasil}

O certificado é um documento emitido pelo Centro Islâmico, quando são preenchidos todos os requisitos de produção Halal. No Brasil, há certificados específicos para frigoríficos, assegurando que a carne Halal foi produzida conforme determina as regras alimentares islâmicas (BRASIL, 2011).

A certificação do produto Halal no Brasil alcança mercados no Oriente Médio, África e Ásia. São feitas por empresas particularizadas como a Central Islâmica Brasileira de Alimentos Halal, reconhecida pela Federação das Associações Mulçumanas do Brasil (FAMBRAS) e o Centro de divulgação Islã para a América Latina (CDIAl) (Khattak, 2011). O certificado é o selo de garantia, pois agrega valores por ser um produto diferenciado, permite a entrada em um mercado que movimenta em torno de 2.5 trilhões de dólares e tem aceitação dos consumidores muçulmanos (BRASIL, 2011).

Segundo a FAMBRAS, o mercado brasileiro de matéria-prima e produtos industrializados Halal crescerá em torno de 15\%em 2016, e aponta que $40 \%$ da carne bovina brasileira e exportada principalmente para o Egito. O consumo interno também irá aumentar, pois a comunidade muçulmana no Brasil já totaliza em torno de um milhão de pessoas (BRASIL, 2011). A exportação, segundo a Associação Brasileira das Indústrias Exportadoras de Carne (ABIEC), foi de 377.871 toneladas de carne Halal para países do Oriente Médio e Norte da África, um aumento de 20,83\% em relação ao ano de 2015.

\section{Considerações finais}

Entendemos que o abate humanitário na forma como é realizado no Brasil atendendo a Instrução Normativa $N^{o} 3$ de 17/01/2000, causa menos sofrimento e preserva o bem-estar animal desde a recepção até a operação de sangria.

A legislação brasileira faculta o sacrifício de animais para atender as exigências e preceitos religiosos para diversos países com bases religiosas judaicas e muçulmanas que seguem os livros sagrados Torá e Alcorão. Mesmo atendendo esses critérios devemos estar atentos e focados o máximo possível no bem-estar animal, para que não haja nenhum tipo de sofrimento desnecessário.

O abate humanitário e a jugulação cruenta são métodos diferentes, cada um com sua particularidade, mas que possuem o mesmo objetivo que é garantir o bem-estar animal e obter carne de qualidade para os seus determinados consumidores.

O Brasil tem interesse econômico nos abates religiosos, pois há um valor agregado nas negociações, aumentam-se as taxas de exportações e geram divisas não só para as indústrias como também para o país como um todo, sendo assim todos saem beneficiados.

\section{Referências Bibliográficas}

ABIEC. 2016. Associação Brasileira das Indústrias Exportadoras de Carnes. Halal e Kosher. São Paulo.

Bannister R., Brain and Bannister's 1992. Clinical Neurology, 7th ed. Oxford: Oxford University, 640p.

Barreto M. \& Castro M. 2004. Selo Kosher oferece segurança. http://www.revistagrill.com.br/vitrine.htm 1. [acesso 11 jun 2016]

Baruch R. P. 2008. Introdução ao abate ritual JudaicoSchechitá. http://pinchasblinder.blogspot.com.br/. [acesso 12 jun 2016]. 
Bitencourt L. 2001. Sob a lâmina da "espada" 4 ed. Revista ABCZ, 9, 2p.

Bonfim L. M. 2003. Abate humanitário de Bovinos: parte II. http://rehagro.com.br/plus/modulos/noticias/le r.php?cdnoticia=513 [acesso 30 mai 2016].

Bonfim L. M. 2005. Diferenças entre Abate ritual (Kosher/Halal) e Abate tradicional, Rehagro. https://pt.scribd.com/doc/45477106/Diferenca s-HALAL-KOSHER. [acesso 16 jun 2017].

BRASIL, 2015. Rebanho bovino brasileiro cresce a 212,3 milhões de cabeças de gado. Portal Brasil. http://www.brasil.gov.br/economia-eemprego/2015/10/rebanho-bovino-brasileirocresce-e-chega-a-212-3-milhoes-de-cabecasde-gado. [acesso 30 mai 2017]

BRASIL. 2016. Associação Brasileira das Indústrias Exportadoras de Carnes. Estatísticas de exportação por ano. http://www.abiec.com.br/41_exportacao_ano. asp [acesso 13 jun 2016].

BRASIL. 2016. Associação Brasileira das Indústrias Exportadoras de Carnes. Exportações de carne bovina brasileira atingem US\$ 5,9 bilhoes em 2015. http://www.abiec.com.br/noticia.asp?id=1415 \#.V2hVNdQrKt8. [acesso 14 jun 2016].

BRASIL. Instrução Normativa $n^{\circ} 3$ de 17 jan 2000. Dispõe sobre o regulamento técnico de métodos de insensibilização para o abate humanitário de animais de açougue [online]. Ministério da Agricultura e Abastecimento. http://www.defesa.agricultura.sp.gov.br/www/ legislacoes/popup.php?action=view \&idleg $=66$ 1 [acesso 30 mai 2017].

BRASIL. 2008. Instrução Normativa $n^{\circ} 56$ de 6nov. Dispõe sobre as recomendações de boas práticas de bem-estar para animais de produção e de interesse econômico. Ministério do Estado da Agricultura, Pecuária e Abastecimento. http://www.agricultura.gov.br/arq_editor/file/ Desenvolvimento_Sustentavel/ProducaoIntegrada-

Pecuaria/IN\%2056\%20de\%202008.pdf. [acesso 30 mai 2016].

BRASIL. 2011. Organização das Nações Unidas para a Alimentação e a Agricultura. Carnes com abate religioso ganham espaço nas agroindústrias brasileiras: Brasil aumenta qualificação para atender mercados como o mulçumano e $\mathrm{o}$ judaico. http://www.fao.org.br/cargeab.asp. [acesso 16 jun 2017].

BRASIL. RIISPOA. Regulação de Inspeção Industrial e Sanitária de Produtos de Origem Animal. Inspeção "ante-mortem". Cap.1 art. 110. Rio de Janeiro, 1952. http://www.agricultura.gov.br/arq_editor/file/ Aniamal/MercadoInterno/Requisitos/Regulam entoInspecaoIndustrial.pdf. [acesso 3jun 2016].

BRASIL. Agrodefesa. Bem-estar e abate humanitário dos animais bovinos. http://www.agrodefesa.go.gov.br/publicacoes/ insp-registro/programas-de-auto-controle/pac16/712-pac-16-bem-estar-e-abatehumanitario-bovinos/file . [acesso 3jun 2016].

DIPOA. Departamento de Inspeção de Produtos de Origem Animal 2017. - Divisão de Inspeção de carnes e derivados. https://alimentusconsultoria.com.br/wpcontent/uploads/2017/03/DECRETON\%C2\%BA-9.013-DE-29-DEMAR\%C3\%87O-DE-2017-1.pdf. [acesso 3 Out 2017].

Ciocca J. R. P., Tseimazides S. P. \& Costa M. P. 2006. Efeitos do transporte no bem-estar e na qualidade da carne. http://www.beefpoint.com.br/efeitos-dotransporte-no-bem-estar-e-na-qualidade-dacarne-29319/. [acesso em 3jun 2017].

Codignoli M. C. F. 2003. A faca chalaf da comida Kosher. Guilda dos Cuteleiros. http://www.netsaber.com.br/apostilas/apostila s/1627.PDF. [acesso 12 jun 2017].

Cortesi M. L. 1994. Slaughterhouses and humane treatment. Paris: Revue Scientifiqueet Tecnique. 13, 171-193.

Costa M. J. R. P. 2013. Spironelli ALG, Quintilano $\mathrm{MH}$. Boas práticas de manejo embarque. Brasília: MAPA, 12-32p.

Costa M. J. R. P., Quintilano M. H. \& Tseimazides S. P. 2010. Boas práticas de manejo transporte. Jaboticabal: Editora Funep, 16, 21.

EUROPA. 2004. European food safety authotity. Welfare aspects of animal stunning and killing methods.

http://www.efsa.europa.eu/sites/default/files/s cientific_output/files/main_documents/45ax1. pdf. 
FAO. Food and Agriculture Organization of the United Nations. 2001. Guidelines for humane handling, transport and slaughter of liverstock. Thailand. http://www.fao.org/docrep/003/x6909e/x6909 e00.htm. [acesso 10 jun 2017]

Finnie J. W. 1993. Brain Damage Caused by a Captive Bolt Pistol. Journal of Comparative Pathology, 109, 253-258.

Gomide L. A., Ramos, E. M. \& Fontes, P, R. 2006. Tecnologia de abate e tipificação de carcaças. Viçosa: Editora UFV, 370p.

Grandin T. 1999. Buenas prácticas de trabajo para El manejo e insensibilización de animales. Fort Collins.

http://www.grandin.com/spanish/Buenas.pract icas.html.

Grandin T. 2012. Maintaining acceptable animal welfare during Kosher or Halal slaughter. http://www.grandin.com/ritual/maintain.welfa re.during.slaughter.html. [acesso 10 Out 2017].

Grandin, T. 2010. ASPCA pen. http://www.grandin.com/ritual/aspca.html. [acesso 12 jun 2017].

Grandin T. 1997. Assessment of stress during handling and transport [online]. Champaing; Journal of Animal Science, 75, 249-257.

Gracey J. F \& Coliins D. S. 2000. Humane slaughter. In:__ Meat hygiene. London: Calouste Gulbekian, 143-167.

Gregory N. G. 1998. Stunning and slaughter. Animal Welfare and Meat Science. Cabi. Publishing.

Gregory N., Lee C. J. \& Widdicombe J. P. 2007. Depth of concussion in cattle shot by penetrating captive bolt. Meat Science, 77, 499-503.

Hedrick H. B., Aberle E. D., Forrest J. C., Judge M. D. \& Merkel R. A. 1994. Principles of meat science. 3 ed. Dubuque: Kendal/Hunt Publ. Co., 354.

IBGE. 2016. Instituto Brasileiro de Geografia e Estatística. Estatística da produção pecuária Brasil;.

http://www.ibge.gov.br/home/estatistica/indic adores/agropecuaria/producaoagropecuaria/ab ate-leite-couroovos_201601_publ_completa.pdf. [acesso 30 mai 2016].
Infante G. J. 2000. Manual de inspeção sanitária de carnes. 2.ed. Lisboa; Calouste Gulbekian, V.2.

Keynes M. 2001. Halal Food Authority. Definition of Halal. http://ucanr.edu/sites/placernevadasmallfarms/ files/103471.pdf. [acesso 15 jun 2017].

Khattak, J. Z. K., Mir, A., Anwar, Z., Wahedi, H. M., Abbas, G., Khattak, H. Z. K., Ismatullah, H. 2011. Concept of Halal food and biotechnology. Advance Journal of Food Science and Technology, 3, 385-388.

Knowles T. G. 1999. A Review of post transport mortality among younger calves. Veterinary Record, 137, 406-407.

Lambooy, E., Spanjaard, W. \& Eikelenboom, G. 1981. Concussion stunning of veal calves. F1eischwirtchaft, 61, 98-100.

Levinger I. M. 1995. Shechita in the light of the year 2000. A Critical review of the scientific aspects of methods of slaughter and Shechita. Mahon, L'David, Jerusalem.

Neves, J. E. G. 2008. Influências de métodos de abate no bem-estar e na qualidade da carne de bovinos. [Tese]. Jaboticabal: Faculdade de ciências agrárias e veterinárias.

Ommaya A. K., Grub R. L. \& Naumann R. A. 1971. Coup and contre-coup injury: observations on the mechanics of visible brain injuries in the rhesus monkey. Journal of Neurosurgery, 503-516.

Pichhi V \& Ajental A. 1993. Abate bovino segundo o ritual judáico. Revista Nacional da Carne, 18, 53-57

Renner R. M. 2006. O manejo pré-abate e seus reflexos na qualidade da carcaça e da carne para a indústria frigorífica. Revista Nacional da Carne, Anuário, 186-198p.

Roça R. \& Serrano A. M. 1995. Influência do banho de aspersão "ante mortem" em parâmetros bioquímicos e microbianos da carne bovina. Pesquisa Agropecuária Brasileira, 30, 1107- 1115.

Roça, R. O. 2001. Abate humanitário: insensibilização e sangria. Revista Nacional da Carne, 290, 45-52.

Roça R. O. 2002. Abate humanitário de bovinos, I Conferência virtual Global sobre produção orgânica de bovinos de corte. 
http://www.cpap.embrapa.br/agencia/congress ovirtual/pdf/portugues/02pt03.pdf. acesso 5 jun 2017].

Snijders J. 1989. Good manufacturing practices in slaughter lines. Fleischwirtschaft, 68, 753756.

Steiner H. 1983. Working Model of Stardadized Techinique for the Hygienic Slaughtering of Catte. Fleischwirtschaft, 63, 1186 - 1187.

Swatland HJ. 2000. Slaughtering. http://www.bert.aps.uoguelph.ca/swatland/ch1 .9.htm. [acesso 10 jun 2016]

Eliasi, J. R. \& Dwyer, J, T. 2002. Kosher and Halal: Religious observances affecting dietary intakes. American Dietetic Association. Journal of the American Dietetic Association; Chicago, 102.7, 911-3.
Tarrant P.V., Kenny F.J., Harrington D. \& Murphy M. 1992. Long distance transportation of steers to slaughter: effect of stocking density and physiology, behaviour and carcass quality. Amsterdam: Livestock Production Science, 30, 223-238.

Thornton H. 1969. Compêndio de inspeção de carnes. Londres: Bailliere Tindall and Cassel; $665 p$.

Article History:

Received 20 July 2017

Accepted 17 August 2017

Available on line 10 October 2017

License information: This is an open-access article distributed under the terms of the Creative Commons Attribution License 4.0, which permits unrestricted use, distribution, and reproduction in any medium, provided the original work is properly cited. 